\title{
Effect of Pulmonary Rehabilitation Training in Non-, Ex- and Current Smokers with Chronic Respiratory Disorders by the Measurement of Functional Capacity: A Pilot Study
}

\author{
Dolly Shah ${ }^{1}$, Anjali Bhise ${ }^{2}$ \\ ${ }^{1}$ BPT, MPT (Cardio-pulmonary), PhD Scholar, Gujarat University. \\ ${ }^{2}$ BPT, MPT (Cardio-pulmonary), PhD in Physiotherapy, The Principal, Govt. Physiotherapy College \& Govt. \\ Spine Institute, Ahmedabad, Gujarat University.
}

Corresponding Author: Dolly Shah

\begin{abstract}
Title: Effect of Pulmonary Rehabilitation Training in Non-, Ex- and Current Smokers with Chronic Respiratory Disorders by the measurement of Functional Capacity: A Pilot Study

Background: Earlier research shows efficacy of pulmonary rehabilitation in chronic lung disorders with regards to their smoking status, but not in all 3 groups together (i.e. Ex-,Never- and Current smokers). So, the goal is to find out effectiveness of pulmonary rehabilitation in chronic lung disorders with regard to their smoking status by the measurement of 6 minute walk distance. This study will help in identifying least benefited to most benefited group among 3 groups by pulmonary rehabilitation .

Methodology :Total 15 patients of both gender and age 30-80 years were randomly selected and divided into 3 groups: Non-, Ex- and Current Smokers with Chronic Respiratory Disorders. Pulmonary Rehabilitation was given for 8 weeks, 3 times / week (30-40 minutes). Pre and Post PR (After 8 weeks), functional capacity was measured by 6 minute walk distance. Data was analyzed by SPSS (v16.0) - One way ANOVA to compare 3 groups and Post Hoc tests to detect the intergroup differences.

Results: Pulmonary Rehabilitation was effective in all 3 groups and Functional Capacity of all patients was improved $(\mathrm{p}<0.05)$. Effectiveness of Pulmonary Rehabilitation was more in NonSmokers compared to Current Smokers. $(\mathrm{p}<0.05)$

Conclusion: Effectiveness of Pulmonary Rehabilitation was significant in all smokers with chronic respiratory disorders but Non- Smokers were more benefited from Current Smokers due to their nonsmoking status. These findings emphasized effectiveness of Pulmonary Rehabilitation and benefits of non-smoking status among patients with chronic respiratory disorders. So, we must encourage measures for smoking cessation at earliest in pulmonary rehabilitation program.
\end{abstract}

Keywords: Functional Capacity, 6 Minute Walk Distance, Pulmonary Rehabilitation, Smokers

\section{INTRODUCTION}

Earlier research has been done showing the efficacy of pulmonary rehabilitation in chronic lung disorders with regards to their smoking status, but not in all 3 groups together (i.e. Ex-,Never- and Current smokers). So, the goal is to find out the effectiveness of pulmonary rehabilitation in chronic lung disorders with regard to their smoking status by the measurement of 6 minute walk distance. This study will help in identifying least benefited to most benefited group among 3 groups by pulmonary rehabilitation training. We can educate patients about serious ill effects of smoking and motivate for 
cessation of smoking. It has been proved that smokers have increased airway reactiveness ${ }^{(1)}$ and decreased exercise tolerance ${ }^{(2)}$. Smokers with chronic respiratory diseases also will have decreased functional capacity. Pulmonary rehabilitation is effective in both - smokers and patients with chronic respiratory diseases. (3,4) So, we wanted to know whether patients smoking behaviour affect the result of pulmonary rehabilitation in all 3 groups by the measurement of functional status in terms of 6 minute walk distance. Exercise intolerance and functional impairment are common consequences of chronic respiratory disease. The distinctive characteristics of exercise intolerance in this population include dyspnea, muscle fatigue, hypoxia, bronchospasm, fear and anxiety surrounding activity. Patients with chronic respiratory disease spend significantly less time walking and standing and more time sitting and lying in daily life when compared to sedentary, healthy age-matched individuals. ${ }^{(5,6)}$ Pulmonary rehabilitation (PR) has been an important adjunctive treatment for chronic obstructive pulmonary disease (COPD), optimizing the level of independence and exercise tolerance with subsequent improvement in quality of life. $(7,8)$

\section{METHOD}

\section{- Sample:}

This study was performed at Pulmonary Rehabilitation Department, Fitness Department, Government Physiotherapy College \& Government Spine Institute, Civil Hospital, Ahmedabad. Total 15 patients of both gender and age group 30-80 years were randomly selected and all were divided into 3 groups (5 patients in each group): Non-, Ex and Current Smokers with Chronic Respiratory Disorders. The smoking index for both groups of smokersEx- and Current was more than 100 as determined by multiplying the number of bidis or cigarettes consumed per day by the number of years of smoking. There were 4COPD, 4- ILD, 2-Asthma, 3-Bronchiectasis,
1-PTB with Chronic Bronchitis, 1-PTB with Emphysema among 15 patients.

- Inclusion Criteria : Never, Ex- and Current Smokers with Chronic Respiratory Disorders

Patients who smoked any tobacco product either daily or occasionally were considered as Current Smokers. Patients who were formerly daily or occasional smokers but currently do not smoke at all and who smoked 100 or more cigarettes (or the equivalent amount of tobacco) in their lifetime were considered as Ex- Smokers. Patients were treated as Ex-Smokers once they had been smoke free for 1 month (at least 28 days). Patients who either have never smoked at all or have never been daily smokers and have smoked less than 100 cigarettes (or the equivalent amount of tobacco) in their lifetime were considered as Non-Smokers.

- Exclusion Criteria : Patients below 30 years and above 80 years, Children, Patients before and after surgery, Pulmonary oedema, Acute Exacerbation, Pulmonary Arterial Hypertension, Lung Cancer, Uncooperative, no willingness to participate, Unconscious Patients

- Materials :

Consent form

Physiotherapy Evaluation Sheet

6MWT Worksheet

Borg Scale

Measure tape, Cone

Proforma paper, Pen, Pencil, Eraser, Table

- Apparatus :

Treadmill

Pulse Oximeter

Sphygmomanometer

Hand held weights-Dumbbells

Postural Drainage Plinth, Chair

Stethoscope

- Procedure:

An informed consent was taken orally as well as in written from all patients participating in this study. Before and After Pulmonary 
Rehabilitation (As per AACVPR Guidelines) (After 8 weeks) each patient was underwent :

$>$ Full history taking and clinical examination

$>$ 6MWTD (As per ATS statement and guidelines for $6 \mathrm{MWT})^{(9)}$

\section{6-Minute walk test (6MWT)}

- Walking is the only activity performed daily by all including severely impaired patients. This test measures the distance that a patient can quickly walk on a flat, hard surface in a period of 6 minutes (the 6MWD). Patients can choose their own intensity of exercise and are allowed to stop and rest during the test. Therefore they do not achieve maximal exercise capacity during the test. Thus, self-paced 6MWT assesses the submaximal level of functional capacity. Most activities of daily living are performed at submaximal levels of exertion, the 6MWD may better reflect the functional exercise level for daily physical activities. The 6MWT is indicated for measuring the response to medical interventions in patients with moderate to severe heart or lung disease, as a one-time measure of functional status of patients and as a predictor of morbidity and mortality.

- The 6MWT should be performed at less crowded indoors or with comfortable weather outdoors, along a long, flat, straight, enclosed corridor with a hard surface. The walking course must be 30 $\mathrm{m}$ in length or 100-ft hallway. The length of the corridor should be marked every $3 \mathrm{~m}$. The turnaround points should be marked with a cone. A starting line, which marks the beginning and end of each 60-m lap, should be marked on the floor using brightly coloured tape. Distance covered by patient after 6 min. walk was calculated and recorded on the 6MWT worksheet. During the test, oxyhemoglobin saturation by pulse oximetry $(\mathrm{SpO} 2 \%)$, heart rate (HR), respiratory rate (RR), blood pressure (BP), Rate of perceived exertion (RPE), rate of perceived breathlessness (RPB), were measured using the Borg categorical scale.

\section{- Interventions:}

Pulmonary Rehabilitation Training was given for total 8 weeks, three times per week (2 times -supervised and onceunsupervised), lasting 30-40 minutes each. Pre and Post Pulmonary Rehabilitation (After 8 weeks), functional capacity of each patient was measured by 6 minute walk distance. The PR program was designed individually, according to the limitations of each patient. It included therapeutic exercise, daily life activities training, breathing control techniques, individualized self-management education and, if indicated, airways clearance and adaptation to long-term oxygen therapy. The three groups were submitted jointly to the same physical training program, based on the recommendations of the American Association of Cardiovascular and Pulmonary Rehabilitation (AACVPR guidelines). ${ }^{(10)}$

- Total of 24 sessions. The program consisted of:

\section{- Breathing Exercises:}

Patients were taught controlled, relaxed diaphragmatic breathing and pursed lip breathing daily for 5 minutes in the starting of the session and during exercise training.

\section{- Exercise Training:}

(1). Warm-up- (10 min.)- Active movements and flexibility training of all joints with stretching exercise of the muscles to be exercised during the session-Hamstring, Quadriceps, Calf, adductors as well as stretching of pectorals.

(2). Training period-(20-25 min.)-

- Lower Extremity Endurance Training Patients were supervised on a treadmill and the speed adjusted by setting a slower speed initially until the patient had mastered the walking technique. Once they were confident and safe 
walking on the treadmill, speed was increased. Patients exercised at Borg scores for dyspnea from 4 to 6 . Patients were advised pursed lip breathing during walking. The training was constantly monitored, and supplemental oxygen was used when a significant decrease in SpO2 $(<90 \%)$ was observed. Patients were not able to walk continuously for 20-30 minutes in the beginning, therefore 10 minutes of continuous walking was started and built up to 2030 minutes as per each patient's capacity and adaptation to the training.

- Cool down-(5 min.)- Slowdown of active movements of all joints and stretching of the muscles exercised during the session.

- Resistance Training: As per need of the patient with the use of weights (hand and ankle weights, free weights, dumbbells), elastic band resistance or using one's body weight such as stair climbing or squats. Strengthening exercises for middle trapezius and rhomboids were given manually to correct posture and improve breathing mechanics .

- Upper limb exercise and Balance Training :Task-specific training of upper limb muscles involved in functional living and trunk muscles exercise were given.

- Bronchial Hygiene/Postural Drainage Technique: Patients with chronic bronchitis and bronchiectasis were advised various positions of postural drainage to facilitate gravity aided drainage. Chest percussion, vibration and shaking were given and taught to patients and their caregivers to perform at home. Patients were asked to do controlled coughing after each position for the removal of secretion.

- Rest period of 5-10 min. were given in between each exercise training.

In addition to Exercise training, weekly educational lectures were delivered to address harmful effects of smoking and smoking cessation, aspects of the disease, activities of daily living, energy conservation, body awareness and nutrition education. Individual instructions were given regarding the use of inhaler devices and use of supplemental oxygen, breathing techniques, postural drainage. Psychosocial and behavioural issues such as depression, anxiety, denial, lack of social and family support were discussed and counselled in patient and family educational sessions.

\section{STATISTICAL ANALYSIS}

Data was analysed by SPSS (v16.0). Analysis of variance (ANOVA) was carried out to compare the responses of 3 groups after 8 weeks of the training program. Post Hoc tests were used to detect the intergroup differences. A probability level of 0.05 was selected as the criterion for statistical significance.

\section{RESULT}

- All 15 patients showed a clinically significant increase in $6 \mathrm{MWD} 30 \leq$ ) $\mathrm{m}$ ) at the end of the program with statistically significant difference between groups. Non-Smokers patients increased the distance by a mean of $102.6 \mathrm{~m}, \mathrm{Ex}-$ Smokers patients increased the distance by a mean of $66.4 \mathrm{~m}$ and Current Smokers patients by a mean of $32.6 \mathrm{~m}$.

- ANOVA revealed that there was a statistically significant difference in 6MWD between at least two groups ( $\mathrm{F}$ $(2,12)=8.570, \mathrm{p}=0.005)$.

- Bonferroni test for multiple comparisons found that the mean value of 6MWD was significantly different between NonSmokers and Current Smokers ( $\mathrm{p}=$ $0.004,95 \%$ C.I. $=[23,117])$. There was no statistically significant difference between Ex-Smokers and Non- Smokers $(\mathrm{p}=0.161)$. There was no statistically significant difference between ExSmokers and Current Smokers $(\mathrm{p}=$ 0.206).

- Thus, Post-PR 6MWD improved in all 3 groups-(Non-Smokers, Ex-Smokers and Current Smokers). ( $\mathrm{p}<0.05)$ Improved 6MWD was more in Non-Smokers 
Dolly Shah et.al. Effect of pulmonary rehabilitation training in non-, ex- and current smokers with chronic respiratory disorders by the measurement of functional capacity: a pilot study.

compared to Current Smokers. $(\mathrm{p}<0.05)$

Improvement in Ex- and Current

Smokers
Improvement in Ex- and Non- Smokers was insignificant.

\begin{tabular}{|c|c|c|c|c|}
\hline \multicolumn{5}{|c|}{ 6MWD- ANOVA \& Post Hoc Test for Multiple Comparisons between 3 groups Post PR } \\
\hline & Mean Difference & Standard Deviation & ANOVA (Between groups and Within groups) & Post Hoc Test-Bonferroni \\
\hline \multirow[t]{2}{*}{ NS } & \multirow[t]{2}{*}{102.60} & \multirow[t]{2}{*}{35.26} & \multirow[t]{6}{*}{$\mathrm{F}(2,72)=8.570, \mathrm{p}=0.005 *(\mathrm{P}<0.05)$} & $\mathrm{ES}, \mathrm{p}=0.161$ \\
\hline & & & & $\mathrm{CS}, \mathrm{p}=0.004 *(\mathrm{P}<0.05)$ \\
\hline \multirow[t]{2}{*}{ ES } & \multirow[t]{2}{*}{66.40} & \multirow[t]{2}{*}{26.57} & & $\mathrm{NS}, \mathrm{p}=0.161$ \\
\hline & & & & $\mathrm{CS}, \mathrm{p}=0.206$ \\
\hline \multirow[t]{2}{*}{$\mathrm{CS}$} & \multirow[t]{2}{*}{32.60} & \multirow[t]{2}{*}{13.95} & & $\mathrm{NS}, \mathrm{p}=0.004 *(\mathrm{P}<0.05)$ \\
\hline & & & & $E S, p=0.206$ \\
\hline
\end{tabular}
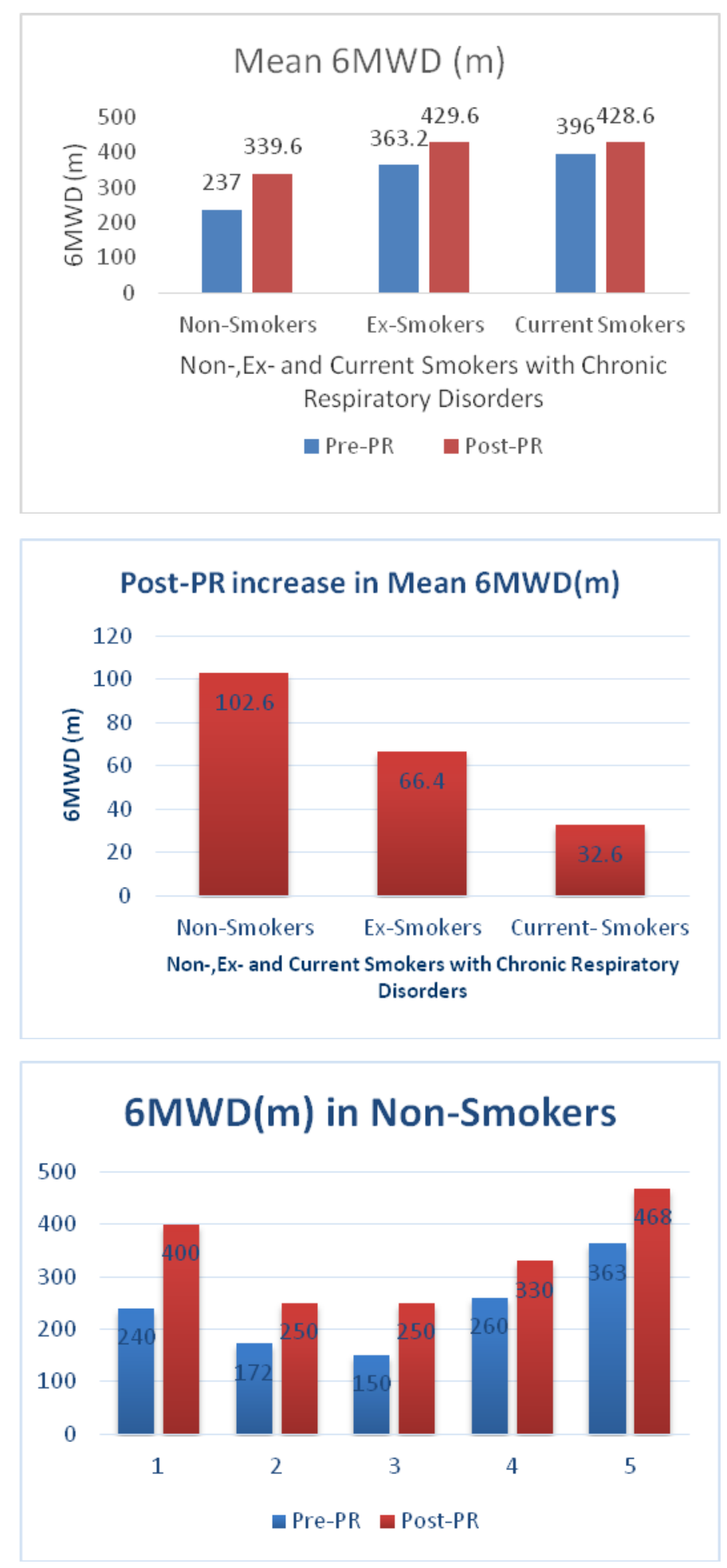


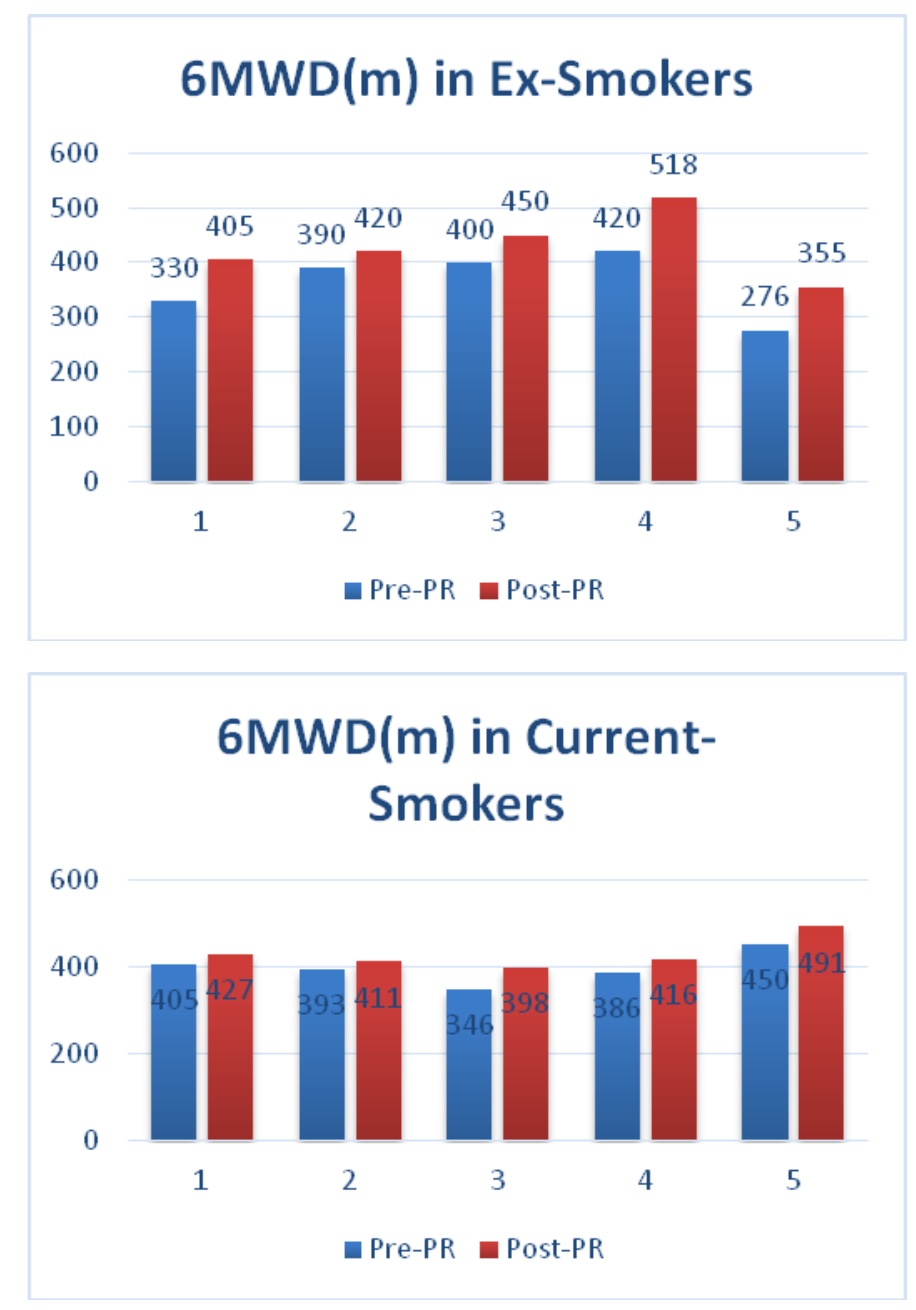

\section{DISCUSSION}

It is well-known fact that Smoking Tobacco causes irreversible lung damage and lung diseases. Pulmonary Rehabilitation is very effective in all chronic respiratory diseases: COPD and Non-COPD patients as well as in Non-, ex and current smokers. Pulmonary Rehabilitation is also effective in Non-, ex- and current smokers with chronic respiratory diseases. The aim was to check whether smoking intensity and history as per three groups affect the outcome i.e. 6 minute walk distance Post PR. In this study, there was an improvement in 6 minute walk distance after PR in all 3 groups compared to their Pre-PR level but improvement in distance was more in Non- smokers group compared to current smokers. Thus, smoking status surely affects patient's outcome. Patients can be made aware about benefits of quitting smoking and induced cessation of smoking at entry level of pulmonary rehabilitation program.

Chronic respiratory diseases like lung cancer, chronic obstructive pulmonary diseases especially chronic bronchitis and emphysema caused by tobacco smoking are strongly linked with major cause of adult mortality .

The cohort study by Doll and Hill demonstrated for the first time that myocardial infarction (heart attack), chronic lung disease (especially bronchitis and emphysema) and various other diseases were also related to smoking and confirmed the higher lung cancer rates among smokers.

US Department of Health and Human Services, A Report of the Surgeon General mentions that the principal nonmalignant respiratory diseases caused by cigarette smoking are COPD, emphysema, chronic bronchitis and idiopathic pulmonary fibrosis. The absolute risk of death of 
Smokers from a specific disease is up to 30 times higher than that of Never Smokers ${ }^{(11)}$.

D Cohen et al and Kreyling WG found that Lungs of Current Smokers and Ex-Smokers will be more affected than Non Smokers due to reduced rate of clearance of very high number of particles in smoke, diffuse changes affecting the lining of the airways, the epithelium, and the structure of the bronchioles and decreased surface area for gaseous exchange in former during rest and exertion ${ }^{(14-11)}$.

Several studies found that active smokers (mild smokers and heavy smokers) had a significantly lower functional capacity (6MWD), lung functions, more work disability and worse quality of life than nonsmokers (NS). ${ }^{(15-19)}$

Study done by M.A.Spruit found that Current Smokers with chronic obstructive pulmonary diseases (COPD) have reduced 6MWT performance compared to Ex-Smokers.(20)Carlos Cabrera Lopez et al found that NonSmokers with COPD walked significantly higher distance in the 6MWT than Smokers with COPD.(21)Few studies found that Current and Ex-Smokers with emphysema and Interstitial Lung Abnormalities (ILA) had measurable decrements in the 6MWD . $(23,22)$

P.I. Pedro et al found increase in 6 minute walk distance in active and former smokers with COPD and ILD post-PR ${ }^{(24)}$.

Several studies found clinically significant similar gain in functional exercise capacity (6MWD) in Current Smokers and Ex-Smokers post-PR ${ }^{(25-27)}$, which supports our findings.

Jose R. Lopes et al and A. G. Siddall et al found similar benefits after PR in terms of improving exercise capacity and peripheral muscle strength in patients with COPD with heavy smoking history of $>40$ pack/years, less heavy smoking history and non-smokers ${ }^{(28,29)}$.

In this study there was an improvement in 6 minute walk distance after PR in all 3 groups compared to their Pre-PR level, which is supported by many studies. Present study found more improvement in distance in Non- Smokers compared to Current Smokers post PR, which is also supported by few studies.

It is well-known fact with extensive data that smoking considerably accelerates the sequential decline in lung function. Smoking is a cause or key risk factor in a number of diseases. Smokers have six times the risk of developing COPD and 10 times the risk of contracting lung cancer compared with non-smokers ${ }^{(30)}$.

Lungs of Current Smokers and ExSmokers will be more affected than Non Smokers due to reduced rate of clearance of very high number of particles in smoke, diffuse changes affecting the lining of the airways, the epithelium, and the structure of the bronchioles and decreased surface area for gaseous exchange in former during rest and exertion. These ultimately reduces the delivery of oxygen to exercising muscles and patients cannot continue exercise further ${ }^{(33-30)}$.

Chemicals in bidi smoke, including nicotine and carbon monoxide causes cardiovascular toxicity by elevating blood $\mathrm{COHb}$ (Carboxyhaemoglobin) which causes tissue hypoxia and increases myocardial oxygen demand. These changes stimulates erythropoiesis-increase in mean haemoglobin, haematocrit and erythrocyte values. ${ }^{(34-39)}$ Thus, less oxygen is delivered to exercising lower extremity muscles and muscle fatigue sets in easily. Few studies found higher Blood $\mathrm{COHb}$ concentrations in bidi smokers than non-smokers. (40-42) Studies have shown that cigarette smokers with $\mathrm{COHb}$ levels chronically elevated over $5 \%$ have a 20-fold increased risk of developing atherosclerosis compared to smokers with lower levels. ${ }^{(9,38)}$

Though Non- Smokers also had chronic respiratory disorders, they were free of the effect of all chemicals present in the tobacco smoke, so they were less affected compared to current and Ex-Smokers. NonSmokers responded very well before, during and after pulmonary rehabilitation than Current and Ex-Smokers in this study. Thus, 
Dolly Shah et.al. Effect of pulmonary rehabilitation training in non-, ex- and current smokers with chronic respiratory disorders by the measurement of functional capacity: a pilot study.

chronically elevated $\mathrm{COHb}$ levels, tissue hypoxia, increased myocardial oxygen demand, greater oxygen debt and higher serum lactate levels lead to cardiovascular toxicity, lower heart rate response on all exercise levels, lower maximal heart rate, and lower maximal working capacity -all contributed for great advantage to NonSmokers than Current Smokers.

Present study found that though pulmonary rehabilitation was effective in all 3 groups of smokers, Non-Smokers with respiratory diseases were at good advantage than Current Smokers with respiratory diseases in terms of functional capacity. Thus, smoking status surely affects patient's outcome.

\section{CONCLUSION}

These findings emphasize effectiveness of Pulmonary Rehabilitation and benefits of non-smoking status among patients with chronic respiratory disorders. So, we must encourage measures for Smoking Cessation at earliest in pulmonary rehabilitation program. Cessation efforts prevent the occurrence and progression of disease in those who quit smoking. We should encourage counselling, combinations of the most effective group programs of smoking cessation, regular exercise, proper nutrition, social and spiritual support behavioural and pharmacological treatment for optimal management of nicotine dependence and improved quit rates. Programs that incorporate the real stories and experiences of those who failed but didn't give up offer hope to a group of people who may be among the best candidates for quitting.

Acknowledgement: None

Conflict of Interest: None

Source of Funding: None

Ethical Approval: Approved

\section{REFERENCES}

1. Ramakant Dixit, Kalpana Dixit, Raghvendra Dixit. Bronchial Hyper responsiveness among Active Smoker, Passive Smoker and Nonsmokers: A Comparative Analysis. Indian $\mathbf{J}$ Allergy Asthma Immunol 2007:21(1):25-30.

2. George Papathanasiou et al .Effects of Chronic Smoking on Exercise Tolerance and on Heart Rate - Systolic Blood Pressure Product in Young Healthy Adults. Eur J Cardiovasc Prev Rehabil Jan 2007: 14:646.652

3. Ries AL, Bauldoff GS, Carlin BW, Casaburi R, Emery CF, Mahler DA, Make B, Rochester CL, ZuWallack R, Herrerias C et al .Pulmonary Rehabilitation: Joint ACCP/AACVPR Evidence-Based Clinical Practice Guidelines .Chest131:4;2007 S$42 \mathrm{~S}$.

4. Salhi B, Troosters T, Behaegel M, Joos G, Derom E. Effects of pulmonary rehabilitation in patients with restrictive lung diseases .Chest.279-137:273;2010

5. Pitta F, Troosters T, Spruit MA, Probst VS, Decramer M, Gosselink R. Chracteristics of physical activity in daily life in chronic obstructive pulmonary disease. Am J Respir Crit Care Med.2005;171:972-977.

6. Hirayama F, Lee AH, Binns CW, Leong CC, Hiramatsu T. Physical activity of patients with chronic obstructive pulmonary disease: implications for pulmonary rehabilitation. JCardiopulmRehabil Prev.334-28:330;2008.

7. American Thoracic Society. Official statement of the American Thoracic Society: pulmonary rehabilitation. Am J Respir Crit Care Med. 1999;159 (5 pt 1):1666-82.

8. Troosters T, Casaburi R, Gosselink R, Decramer M. Pulmonary rehabilitation in chronic obstructive pulmonary disease. Am J Respir Crit Care Med.2005;172(1):19-38.

9. American Thoracic Society,2002,"ATS Statement: Guidelines for the six minute walk test",American journal of respiratory and critical care medicine, Issue 1;166:111117.

10. American Association of Cardiovascular and Pulmonary Rehabilitation,2011, Guidelines for pulmonary rehabilitation programs/American Association of Cardiovascular and Pulmonary Rehabilitation(AACVPR). $-4^{\text {th }}$ edition. 
Dolly Shah et.al. Effect of pulmonary rehabilitation training in non-, ex- and current smokers with chronic respiratory disorders by the measurement of functional capacity: a pilot study.

11. How Tobacco Smoke Causes Disease: The Biology and Behavioral Basis for SmokingAttributable Disease: A Report of the Surgeon General. Atlanta, GA: U.S. Department of Health and Human Services, Centers for Disease Control and Prevention, National Center for Chronic Disease Prevention and Health Promotion, Office on Smoking and Health, 2010.

12. D Cohen, SF Arai ,JD Brain. Smoking impairs long-term dust clearance from the lung Science May 1979:Vol. 204, Issue 4392, pp. 514-517.

13. US Department of Health and Human Services.The Health Consequences of Smoking: Chronic Obstructive Lung Disease A Report of the Surgeon General .Office on Smoking and Health; 1984. DHHS Publication No. (PHS) 84 .50205

14. Kreyling WG, Scheuch G. 2000. Clearance of particles deposited in the lungs. In: Particle-Lung Interactions (Gehr P, Heyder J, eds). New York/Basel:Marcel Dekker, 323.376-

15. L-P Boulet, JM FitzGerald, RA McIvor, S Zimmerman, KR Chapman. Influence of current or former smoking on asthma management and control. Can Respir J 2008;15(5):275-279.

16. R. Chaudhuri et al. Role of symptoms and lung function in determining asthma control in smokers with asthma. European journal of allergy and clinical immunology Vol.63,Issue 1, January 2008,Pages 132135.

17. Sandvik L, Erikssen G, Thaulow E. Long term effects of smoking on physical fitness and lung function: a longitudinal study of 1393 middle aged Norwegian men for seven years. BMJ. 1995; 311: 715 18. )

18. Helmi Ben Saad et al.Investigation of Exclusive Narghile Smokers: Deficiency and Incapacity Measured by Spirometry and 6-Minute Walk Test.Respiratory Care July 2014, respcare. 03058

19. Rafaella Xavier, Dionei Ramos, Fernanda R odrigues et al. Effects of cigarette smoking intensity on functional capacity of active smokers.European Respiratory Journal. 2013. 42: P1334.

20. MA Spruit, JM Seymour, J Moxham, MI Polkey, EFM Wouters. Reduced 6 minute walking test performance in current smokers with chronic obstructive pulmonary disease.
Thorax 2008;63(Suppl VII):A74A160Carlos Cabrera Lopez, Ciro Casanova Mac

21. Carlos Cabrera Lopez et al. Differences in COPD: Smokers versus non smokers. European Respiratory Journal. 2015. 46: PA4077; DOI: 10.1183/13993003.congr ess-2015.PA4077

22. Tracy J. Doyle et al. Interstitial Lung Abnormalities and Reduced Exercise Capacity, Am J Respir Crit Care Med.,2012 Apr 1; 185(7): 756-762.

23. Ana B. Alcaide et al.Clinical Features of Smokers With Radiological Emphysema But Without Airway Limitation. Chest. 2017 Feb;151(2):358-365. doi: 10.1016/ j.chest.2016.10.044.

24. P I Pedro, L Maia Santos, C Braço Forte et. al. Benefits of pulmonary rehabilitation in patients with chronic obstructive pulmonary disease and interstitial lung disease with the same dyspnea severity. Pulmonology. MarApr 2019;25(2):117-118. doi: 10.1016/j.pulmoe.2019.01.002.

25. Vivian T. S. Santana et al. Influence of current smoking on adherence and responses to pulmonary rehabilitation in patients with COPD. Brazilian Journal of Physical Therapy. 2010, vol.14, n.1, pp.1623.

26. Abdessalem Koubaa et al. Lung function profiles and aerobic capacity of adult cigarette and hookah smokers after 12 weeks intermittent training.Libyan $\mathrm{J}$ Med 2015, 10: 26680.

27. I Hill, AJ Williams, TJ Shaw. P41 Should smokers be allowed to pulmonary rehabilitation? Thorax 2008;63(Suppl VII):A74-A160.

28. Jose R. Lopes et al. Effects of smoking history on the benefits of pulmonary rehabilitation in patients with COPD European Respiratory Journal. 2017. 50: PA3720.

29. G. Siddall et al. Smoking status and physical fitness during initial military training.Occupational Medicine.2017 Apr 1;67(3):205-210.

30. Office of the Surgeon General (US), Office on Smoking and Health (US). The Health Consequences of Smoking: A Report of the Surgeon General [Internet]. Atlanta (GA): Centers for Disease Control and Prevention (US); 2004 [cited 2021 Mar 15]. (Reports of the Surgeon General). Available from: 
Dolly Shah et.al. Effect of pulmonary rehabilitation training in non-, ex- and current smokers with chronic respiratory disorders by the measurement of functional capacity: a pilot study.

http://www.ncbi.nlm.nih.gov/books/NBK44 695/

31. Centers for Disease Control and Prevention (US), National Center for Chronic Disease Prevention and Health Promotion (US), Office on Smoking and Health (US). How Tobacco Smoke Causes Disease: The Biology and Behavioral Basis for SmokingAttributable Disease: A Report of the Surgeon General [Internet]. Atlanta (GA): Centers for Disease Control and Prevention (US); 2010 [cited 2021 Mar 15]. (Publications and Reports of the Surgeon General). Available from: http://www.ncbi.nlm.nih.gov/books/NBK53 017/

32. Cohen D, Arai SF, Brain JD. Smoking impairs long-term dust clearance from the lung. Science. 1979 May 4;204(4392):514 .7

33. Kreyling W, Scheuch G, Gehr P, Heyder J. Clearance of particles deposited in the lungs. In: Particle-Lung Interactions. New YorkBaselMarcel Dekker. 2000;323 .76-

34. Office on Smoking and Health. PHS. The Health Consequences of Smoking: Cardiovascular Disease: A Report of the Surgeon General. In Rockville,MD: U.S. Department of Health and Human Services, Public Health Service,: DHHS publication no. DHHS (PHS) 84-50204; 1983.

35. John RM. Tobacco consumption patterns and its health implications in India. Health Policy Amst Neth. 2005 Feb;71(2):213 .22-
36. Rahman M, Fukui T. Bidi smoking and health. Public Health. 2000 Mar;114(2):1237

37. Krupski WC. The peripheral vascular consequences of smoking. Ann Vasc Surg. 1991 May;5(3):291-304 .

38. Zevin S, Gourlay SG, Benowitz NL. Clinical pharmacology of nicotine. Clin Dermatol. 1998 Oct;16(5):557-64

39. Sreerama KK, Venkatramana $P$, Chengal PR. Beedi smoking and hematological variation. Arch Environ Health. 1997 Apr;52(2):150 .

40. Behera D, Dash S, Dinakar M. Correlation of smoking behaviour and blood carboxyhaemoglobin in bidi and cigarette smokers. Indian $\mathbf{J}$ Chest Dis Allied Sci. 1991 Mar;33(1):43.6-

41. Behera D, Dash S, Dinakar M. Blood Carboxyhaemoglobin Levels in Indian Bidi and Cigarette Smokers. Respiration. 1991; 58(1):26.8-

42. Behera D, Dash S, Sen S. Neutrophil count and myeloperoxidase activity in Indian bidi smokers. Respir Int Rev Thorac Dis. 1994;61(5):269-73-

How to cite this article: Shah D, Bhise A. Effect of pulmonary rehabilitation training in non-, exand current smokers with chronic respiratory disorders by the measurement of functional capacity: a pilot study. Int J Health Sci Res. 2021; 11(8): 48-60. DOI: https://doi.org/10. 52403/ijhsr.20210808

\section{ANNEXURE-1}

\section{DEFINITION OF SMOKERS [World Health Organization-WHO]}

- Any population can be divided into two categories, Smokers and Non-Smokers

- A smoker is someone who, at the time of the survey, smokes any tobacco product either daily or occasionally.

- Smokers may be further divided into two categories:

- Al A daily smoker is someone who smokes any tobacco product at least once a day (with the exception that people who smoke every day, but not on days of religious fasting, are still classified as daily smokers).

- $\mathrm{A} 2$ an occasional smoker is someone who smokes, but not every day. Occasional smokers include:

- A2 i) Reducers - people who used to smoke daily but now do not smoke every day.

- A2 ii) Continuing occasional- people who have never smoked daily, but who have smoked 100 or more cigarettes (or the equivalent amount of tobacco) and now smoke occasionally. 
Dolly Shah et.al. Effect of pulmonary rehabilitation training in non-, ex- and current smokers with chronic respiratory disorders by the measurement of functional capacity: a pilot study.

- A2 iii) Experimenters - people who have smoked less than 100 cigarettes (or the equivalent amount of tobacco) and now smoke occasionally.

- B Non-Smoker is someone who, at the time of the survey, does not smoke at all.

- Non-smokers can be divided into three categories:

- Bl Ex-smokers are people who were formerly daily smokers but currently do not smoke at all.

- B2 Never-smokers are those who either have never smoked at all or have never been daily smokers and have smoked less than 100 cigarettes (or the equivalent amount of tobacco) in their lifetime.

- B3 Ex-occasional smokers are those who were formerly occasional, but never daily, smokers and who smoked 100 or more cigarettes (or the equivalent amount of tobacco) in their lifetime.

- These definitions can be used to classify the population according to their lifetime smoking status. In particular:

- C Ever smokers are defined as those who have ever smoked at least 100 cigarettes (or the equivalent amount of tobacco) in their lifetime.

- A specific subcategory of interest is those who have smoked, or now smoke, every day.

- C 1 Ever daily smokers are defined as persons who are currently daily smokers, reducers or ex-smokers.

- $\quad$ Smokers $=$ daily smokers $(\mathrm{Al})+$ occasional smokers $(\mathrm{A} 2$ (i-iii) $)$

- Ever smokers= daily smokers $(\mathrm{AI})+$ occasional smokers $(\mathrm{A} 2(\mathrm{i}-\mathrm{iii}))+$ ex-smokers $(\mathrm{B} 1)$ +ex-occasional smokers (B3)

- Ever daily smokers= daily smokers $(\mathrm{Al})+$ +reducers $(\mathrm{A} 2 \mathrm{i})+\mathrm{ex}$-smokers $(\mathrm{Bl})$

- Ex-smokers= ex-daily smokers (B1)

- Smokeless tobacco use: The above definitions apply equally well to smokeless tobacco use (e.g. snuff, betel-quid chewing, other chewing tobacco).

- Tobacco user is a person who is either a smoker or a smokeless tobacco user, or both.

\section{Informed Consent Document}

\section{Project title:}

"Effect Of Pulmonary Rehabilitation Training In Never, Ex- And Current Smokers With Chronic Respiratory Disorders By The Measurement Of Functional Capacity: A Pilot Study."

\section{Introduction:}

You are invited to participate in a pilot study. It is important that you read this description of the study and understand your role in it including the nature and risks of participation. Please give your consent to participate in this clinical study only if you have completely understood the nature and course of the study and if you are aware of your rights as a participant.

3. Purpose of study :

To determine the effect of Pulmonary Rehabilitation in patients having Chronic Respiratory Disorders with regard to their Smoking Status.

1. To improve Functional Capacity.

2. To provide better understanding of smoking status and its risk associated with chronic respiratory disorders

4. Expected duration of the study and number of subjects :

The Pulmonary Rehabilitation program will be carried out for total 8 weeks, three times per week (2 times- supervised and once-unsupervised), lasting 30-40 minutes each.

\section{Study procedure to be followed}


If you agree to participate in this study, thorough evaluation of your condition or disease will be carried out in the form of full history taking and clinical examination with the performance of 6 Minute Walk Test. As walking is considered to be daily routine activity, 6 Minute walk test is performed by the patient to know his/her functional capacity under supervision of Physiotherapist. You will have to walk as far as possible for 6 minutes. The distance walked during 6 minutes will be measured.

After this, the Pulmonary Rehabilitation program will be carried out for total 8 weeks, three times per week ( 2 times -supervised and once-unsupervised), lasting 30-40 minutes each. Exercise training will be consisted of

Warm-up-(10 min.)-Active movts. Of all joints with stretching exercise,

Training period-(20-25 min.)-Upper and Lower Extremities Endurance training, Resistance Training as per need of the patient

Cool down-(5min.) - Slowdown of active movts. Of all joints

In addition to Exercise training, weekly educational lectures will be delivered to address harmful effects of smoking, smoking cessation, aspects of the disease, activities of daily living, energy conservation, body awareness and nutrition education.

After Pulmonary Rehabilitation (After 8 weeks), you will again underwent:

$>$ Full history taking and clinical examination

6 Minute Walk Test

6. Risks and discomforts of participating :

There are no risks associated with this study, the time spent may be a probable inconvenience to you .You may feel slight dyspnea and fatigue during or after the exercise session as the result of physiologic response of your body to exercise.

7. Possible benefits of this study :

After completion of study, you will become aware of benefits of pulmonary rehabilitation in improving exercise capacity with your disease. You will also come to know that how smoking status affects the result of pulmonary rehabilitation. You may understand the benefits of smoking cessation and exercise training in chronic respiratory disease.

8. What happens when the research study stops ?

If the research study stops, it won't affect your general health status or profession. As pulmonary rehabilitation improves patient's exercise capacity, quality of life and general well-being with no adverse effects, you can follow and continue same regimen at home as per the instructions given as maintenance program. Your routine assessment and treatment at hospital will continue even after the research study stops/completed as per the requirement.

9. Compensation for participation :

Participation in this study will be at no cost to you. The physical test will be done free of charge. It is an interventional study where your routine assessment will be continued. The participation in the study will be provided with your consent and as per your time of convenience .So, no compensation will be provided for your participation .

10. Treatment and compensation for study related injury :

You will be provided medical treatment at this institute for any aggravating signs and symptoms of your disease i.e. acute exacerbation of the disease or physical aches or pain that occurs as a direct result of your participation in this study. This medical treatment will be at no cost to you. You will not give up any of your legal rights by signing in this form .

11. Right to withdraw from the study :

Participation in this study is entirely voluntary. You may choose not to take part or you may leave the study at any time during the physical test. Your decision will not affect 
Dolly Shah et.al. Effect of pulmonary rehabilitation training in non-, ex- and current smokers with chronic respiratory disorders by the measurement of functional capacity: a pilot study.

your future treatment at this institute. If you do not wish to participate in the present study, there will be no effect on your general health status or employment .

12. Confidentiality :

All study records will be kept confidential at all times. Your identity will not be revealed except as required by law. The results of your treatment may be published for scientific reasons. Your identity will not be revealed in these publications .

13. Contact for further information :

Thank you for taking time to read (or have read to you) the information about this study. Before you sign this document, you should ask questions about anything that you do not understand. The study staff will answer all your questions before, during and after the study

If you have questions about this study or how it is being run or possible research related queries, you can contact -------Dolly Shah, Contact Number-7046041122-

If you have any questions about your rights as a research participant, or complaints regarding the research study, you should call Member Secretary of Institutional Ethics Committee on the following telephone number on working days

\section{Consent}

I have read the information given in the Informed Consent document for this pilot study entitle

"Effect of Pulmonary Rehabilitation Training in Never, Ex- And Current Smokers with Chronic Respiratory Disorders by the Measurement of Functional Capacity: A Pilot Study."

1. I have received an explanation of the nature, purpose, duration, foreseeable effects, risks of trial and what I will be expected to do. My questions have been answered satisfactorily .

2. I understand that my participation in the trial is voluntary and that I may refuse to participate or may withdraw from the trial, without penalty or loss of benefits to which I am otherwise entitled .

3. I further understand that any information that becomes available during the course of the study that may affect my willingness to take part in the study will be informed to me .

4. Institutional review board authorities may wish to examine my medical records to verify the information collected. By signing this document, I give permission for this review of my records .

5. I understand that my identity will not be revealed in any report or publication .

6. I agree to take part in the above study .

\begin{tabular}{|c|c|c|}
\hline Name of participant & $\begin{array}{l}\text { Signature/Thumb impression } \\
\text { Of participant }\end{array}$ & Date \\
\hline Name of Impartial witness & $\begin{array}{l}\text { Signature of Impartial } \\
\text { Witness }\end{array}$ & Date \\
\hline $\begin{array}{l}\text { Name of the person } \\
\text { Administering consent }\end{array}$ & $\begin{array}{l}\text { Signature of the person } \\
\text { Aadministering consent }\end{array}$ & Date \\
\hline
\end{tabular}

